Çukurova Üniversitesi Mühendislik Mimarlık Fakültesi Dergisi, 32(4), ss. 163-174, Aralık 2017

\title{
Şekerbulak (Diyadin-Ağrı) Dolaylarında Yüzeyleyen Volkanik Kayaçların Mineralojik-Petrografik ve Jeokimyasal Özellikleri
}

\author{
Mustafa AÇLAN ${ }^{* 1}$, İnci Kibariye TURGUT ${ }^{1}$ \\ ${ }^{1}$ Van Yüzüncü Yıl Üniversitesi, Mühendislik Fakültesi, Jeoloji Mühendisliği Bölümü, Van
}

Geliş tarihi: 03.07.2017 Kabul tarihi: 00.00.2016

\begin{abstract}
$\ddot{O} \mathbf{z}$
Bu çalışma, Ağrı ilinin yaklaşık $40 \mathrm{~km}$ güneydoğusunda yer alan Şekerbulak dolaylarında yüzeyleyen volkanik kayaçların mineralojik-petrografik ve jeokimyasal incelenmesini konu almaktadır. Bölgede plütonik ve volkanik birimler gözlenmektedir. Plütonik birimleri tonalit, granodiyorit, monzogranit ve granit türü kayaçlarda oluşan ve Taşlıçay Granitoidi olarak tanımlanan granitoidler temsil etmektedir. Volkanik birimler ise Yeltepe Trakiandeziti ve Yuva Riyoliti'dir. Bu birimler subalkali, kalkalkali, yüksek K'lu seri ve şoşonitik özellik sergilerler. Buna ek olarak hafif nadir toprak elementleri (LREE) ve iri katyonlu litofil elementler (LILE) açısından zenginleşme gösterirler. $\mathrm{Bu}$ zenginleşme kabuksal kirlenmeyi işaret etmektedir.
\end{abstract}

Anahtar Kelimeler: Şekerbulak, Trakiandezit, Volkanik kayaçlar, Riyolit, Tüf

\section{Mineralogical-Petrographical and Geochemical Properties of the Volcanic Rocks Surrounding Şekerbulak (Diyadin-Ağrı)}

\begin{abstract}
This study is about the mineralogical, petrographic and geochemical investigation of the volcanic rocks around Şekerbulak that is about $40 \mathrm{~km}$ southeast of Ağrı province. Plutonic and volcanic rocks are observed in the region. The plutonic units which is called as Taşliçay Granitoid are in tonalite, granodiorite, monzogranite and granite composition. Volcanic units consist of the Yeltepe Trachyandesite and Yuva Riyoliti. These units exhibit subalkaline, calcalkaline, high K series and shoshonitic features. In addition, they exhibit enrichment in light rare earth elements (LREE) and large ion lithophile elements (LILE). This enrichment is indicative of crustal contamination.
\end{abstract}

Keywords: Şekerbulak, Trachyandesite, Volcanic rocks, Riolite, Tuff

*Corresponding author (Sorumlu yazar): Mustafa AÇLAN, maclan@yyu.edu.tr 


\section{GíRiş}

Doğu Anadolu Bölgesi volkanizma ve volkanik kayaçlar açısından Türkiye'nin en zengin bölgelerinden birisidir. Bölgede irili ufaklı birçok volkan mevcut olup Nemrut, Süphan, Tendürek ve Ağrı volkanları bunlardan en önemlileridir. $\mathrm{Bu}$ bölgede bugüne kadar volkanizma ve volkanik kayaçlarla ilgili birçok çalışma yapılmıştır [1-14]. Çalışma alanı Ağrı İli’nin yaklaşık $40 \mathrm{~km}$ güney doğusunda yer almaktadır (Şekil 1). Bu çalışma Şekerbulak (Diyadin-Ağrı) dolaylarında yüzeyleyen volkanik kayaçların mineralojikpetrografik ve jeokimyasal özelliklerinin belirlenmesi amacıyla yapılmıştır.

Çalışma alanının jeoloji haritası Şekil 1'de, genelleştirilmiş stratigrafik dikme kesiti Şekil 2'de verilmiştir. Çalışma alanında temeli Paleozoyik yaşında olan Batıbeyli metamorfikleri (mermer, kuvarsit ve Biyotit-Muskovit-Kuvars Şistler) oluşturur. Alt Miyosen yaşlı Taşlıçay granitoidleri (granit monzogranit, granodiyorit, tonalit) bu birimleri intrüzif olarak kesmektedir. PliyosenKuvaterner yaşlı Yeltepe trakiandeziti, Taşlıçay granitoidleri üzerine uyumsuz olarak gelmektedir. Kuvaterner yaşlı Yuva riyoliti ve riyolitik tüf bu birimler üzerinde uyumlu olarak bulunmaktadır (Şekil 2).

\section{MATERYAL VE METOT}

Bu çalışma, Ağrı İli Diyadin İlçesi'nin 24 km güneybatısında yer alan $187 \mathrm{~km}^{2}$ 'lik alanı kapsamaktadır. Çalışma ile bölgede yer alan özellikle volkanik kayaçların mineralojikpetrografik ve jeokimyasal özelliklerinin ortaya konulması amaçlanmıştır. $\mathrm{Bu}$ amaçla çalışma alanında yer alan kayaçlardan, kimyasal analize ve mineralojik-petrografik incelemeye yönelik olarak kayaçların en taze bölümlerinden toplam 13 volkanik kayaç örneği alınmıştır.

Araziden toplanan kayaç örneklerinin tamamının petrografik ince kesitleri Yüzüncü Yıl Üniversitesi Jeoloji Mühendisliği Bölümü incekesit laboratuvarında hazırlanmıştır. Kayaçların petrografik tanımlanmaları Jeoloji Mühendisliği Bölümünde polarizan mikroskobu ile gerçekleştirilmiştir. Mikroskopik incelemeler sonucunda en taze ve karakteristik olduğuna inanılan 11 adet kayaç örneğinin tüm kayaç ana ve eser element analizleri ACME laboratuvarlarında (Kanada) yaptırılmıştır.

\section{BULGULAR}

\subsection{Petrografi}

Çalışma alanındaki volkanik birimlerden Yeltepe Trakiandezit'ini oluşturan kayaçlara ait örnekler (K-2, K-3, K-8) mikrolitik porfirik doku (Şekil 4a), hyaloporfirik doku ve hyalomikrolitik porfirik dokuya sahiptiler ve plajiyoklaz, olivin, ojit ve opak minerallerden oluşmaktadırlar.

Riyolit'i oluşturan kayaçlarda (K-4, K-58, K-6, K7, K-9, K-10, K-11) mikrolitik porfirik doku, mikrografik doku, mikrogranüler doku, trakitik doku ve sferolitik dokuları (Şekil 4b) mevcuttur ve bu kayaçlar ortoklaz, plajiyoklaz, kuvars, mikroklin, biyotit, muskovit, klorit, epidot, prehnit ve opak minerallerden oluşmaktadırlar.

Sivrice Tüf'üne ait örneklerde (K-1) hyaloporfirik doku gözlenmiştir. Çalışma alanındaki riyolitik tüf, riyolit ve andezit gibi kayaç parçaları (Şekil 4c,d) ile kuvars, ortoklaz, plajiyoklaz, biyotit ve epidot minerallerinden meydana gelmektedir. Bu tüflerde kloritleşme, epidotlaşma ve zeolitleşme türü ayrışımlar yaygın olarak gözlenmektedir.

\subsection{Jeokimya}

Çalışma alanındaki volkaniklere ait ana element analiz sonuçları Çizelge 1, eser element analiz sonuçları Çizelge 2'de verilmiştir.

Ana element verileriyle ilișkili olarak olarak hazırlanan toplam alkali $\left(\% \mathrm{Na}_{2} \mathrm{O}+\mathrm{K}_{2} \mathrm{O}\right)$-silis $\left(\mathrm{SiO}_{2}\right)$ [15] diyagramında (Şekil 5) çalışma alanındaki volkanik kayaçlar trakiandezit ve riyolit alanına düşmektedirler. Örneklerin Irvine ve Baragar [15]'ın TAS diyagramında tamamen 
subalkali (Şekil 6); Peccerillo ve Taylor [16]'ın $\mathrm{SiO}_{2}-\mathrm{K}_{2} \mathrm{O}$ diyagramında yüksek $\mathrm{K}$ 'lu ve şoşonitik özellik sergileyen bölgede yer aldıkları gözlenmektedir (Şekil 7). Irvine ve Baragar [15]'ın AFM diyagramında ise tüm volkanik birimler kalkalkali özellik sergilemektedir (Şekil 8).

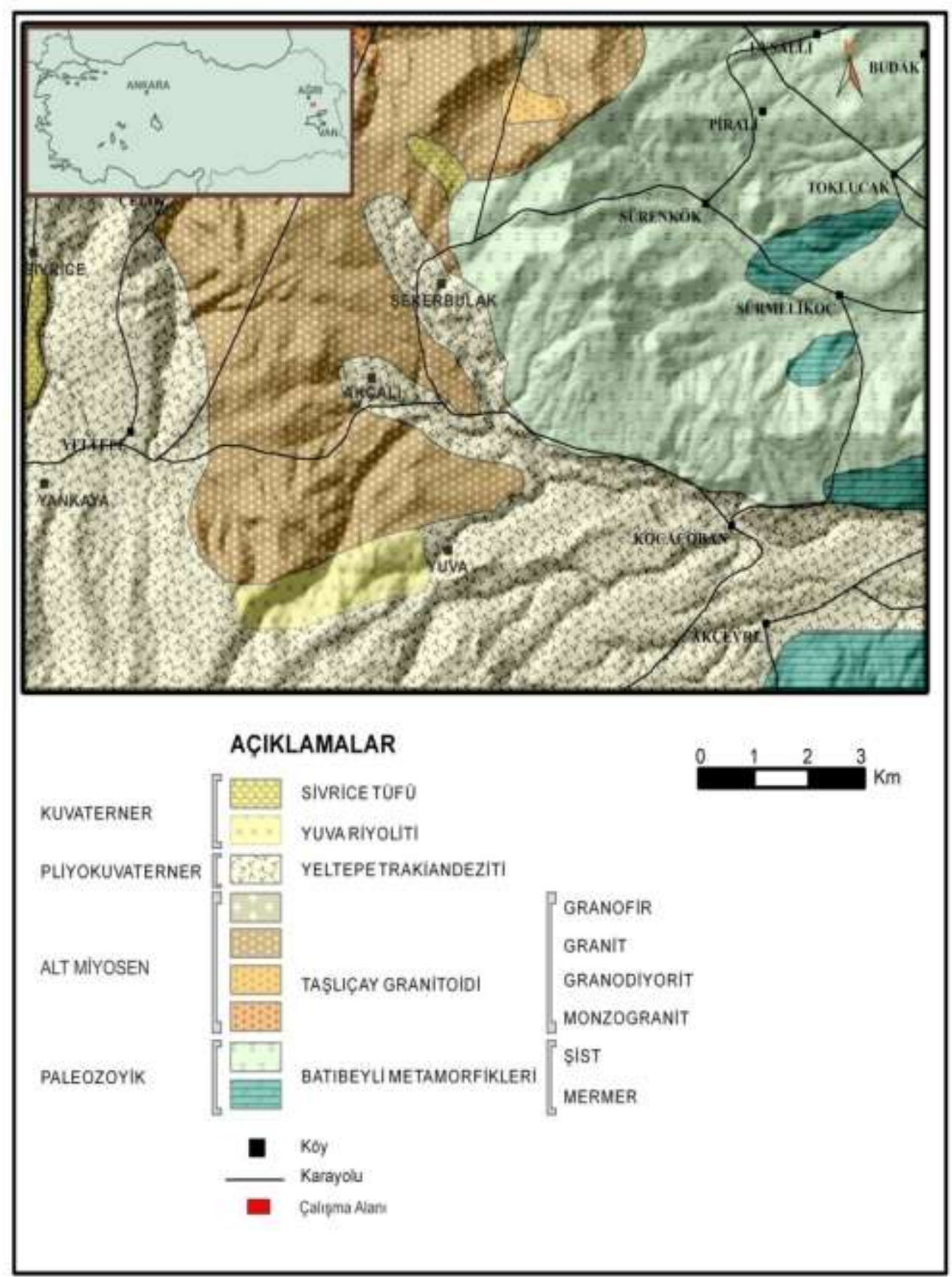

Şekil 1. Çalışma alanının 1/25.000 ölçekli jeoloji haritası [18] 
Şekerbulak (Diyadin-Ağrl) Dolaylarında Yüzeyleyen Volkanik Kayaçların Mineralojik-Petrografik ve Jeokimyasal Özellikleri

\begin{tabular}{|c|c|c|c|c|}
\hline YAS & $\begin{array}{l}\text { FonMLAYYoN } \\
\text { itTODEM }\end{array}$ & 产 & $\begin{array}{l}\text { LTOLOA: } \\
\text { LTODIM }\end{array}$ & ACYIKLAMALAR \\
\hline \multirow{2}{*}{ KUVATERNER } & Sivrice Tüu & Qst & & Riyolitik Tuf \\
\hline & Yuva Riyoliti & Qyr & & Riyolit \\
\hline $\begin{array}{l}\text { PLVYOSEN. } \\
\text { KUVATERNER }\end{array}$ & $\begin{array}{c}\text { Yeltepe } \\
\text { Trikianderiti }\end{array}$ & PQQy & & Traki-Anderit \\
\hline $\begin{array}{l}\frac{3}{y} \\
\frac{y}{2} \\
\frac{1}{2}\end{array}$ & $\begin{array}{l}\text { Tashlyay } \\
\text { Ginnitoidi }\end{array}$ & Ttg & & $\begin{array}{l}\text { Granit } \\
\text { Monzogranit }\end{array}$ \\
\hline PALEOZOYIK & $\begin{array}{c}\text { Batbeyli } \\
\text { Metansorfikleri }\end{array}$ & Phen & & Sist \\
\hline & & & & Mermer \\
\hline
\end{tabular}

Şekil 2. Çalışma alanının genelleştirilmiş stratigrafik dikme kesiti (Ölçeksiz) [18]
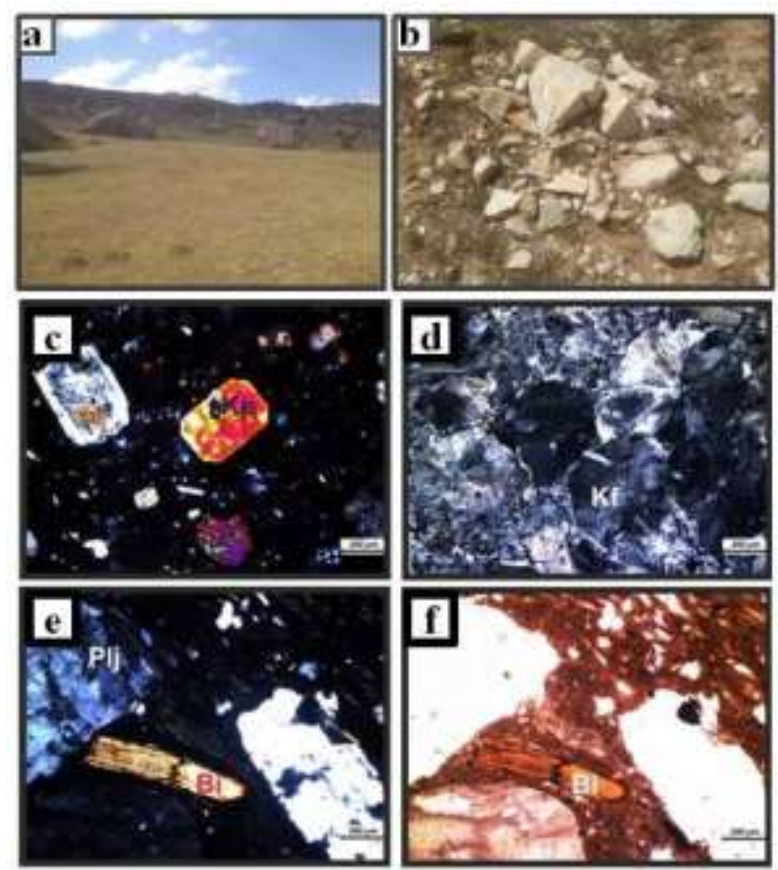

Şekil 4. Şekerbulak (Diyadin-Ağrı) civarındaki volkanik kayaçların arazi ve mikroskop görüntüleri: a) Trakiandezitin arazi görüntüsü b) Riyolitin arazi görüntüsü c) Trakiandezit d) Riyolit; (e-f) Riyolitik Tüf. Plj:Plajiyoklaz, Kp: Klinopiroksen, Kf: Potasyum feldispat, Bi: Biyotit; a,b,c: Çift Nikol; d: Tek Nikol 
Çizelge 1. Çalışma alanındaki volkanik birimlerin ana element jeokimyasal analiz sonuçları (ana element sonuçları $\%$ oksit cinsinden verilmiştir)

\begin{tabular}{|c|c|c|c|c|c|c|c|c|c|c|c|c|}
\hline Örnek No & $\mathbf{S i O}_{\mathbf{2}}$ & $\mathbf{A l}_{\mathbf{2}} \mathbf{O}_{\mathbf{3}}$ & $\mathbf{F e}_{\mathbf{2}} \mathbf{O}_{\mathbf{3}}$ & $\mathbf{M g O}$ & $\mathbf{C a O}$ & $\mathbf{N a}_{\mathbf{2}} \mathbf{O}$ & $\mathbf{K}_{\mathbf{2}} \mathbf{O}$ & $\mathbf{T i O}_{\mathbf{2}}$ & $\mathbf{P}_{\mathbf{2}} \mathbf{O}_{\mathbf{5}}$ & $\mathbf{M n O}$ & $\mathbf{A K}$ & $\mathbf{T o p l a m ~}$ \\
\hline $\mathbf{K - 1 2}$ & 66,94 & 15,99 & 3,36 & 0,65 & 1,51 & 5,11 & 4,81 & 0,71 & 0,17 & 0,10 & 0,4 & 99,75 \\
\hline $\mathbf{K}-15$ & 62,28 & 16,49 & 5,10 & 1,73 & 3,85 & 4,81 & 3,45 & 0,92 & 0,38 & 0,11 & 0,6 & 99,72 \\
\hline $\mathbf{K}-16$ & 60,14 & 17,10 & 5,89 & 1,79 & 4,28 & 4,77 & 3,20 & 1,01 & 0,43 & 0,14 & 1,0 & 99,75 \\
\hline K-17 & 74,91 & 13,68 & 1,10 & 0,21 & 0,25 & 2,17 & 5,91 & 0,15 & 0,03 & 0,02 & 1,4 & 99,83 \\
\hline K-18 & 76,53 & 12,83 & 0,98 & 0,13 & 0,18 & 2,74 & 5,27 & 0,12 & 0,01 & 0,01 & 1,0 & 99,80 \\
\hline K-19 & 69,81 & 15,09 & 2,17 & 0,31 & 0,63 & 4,93 & 5,66 & 0,53 & 0,08 & 0,08 & 0,5 & 99,79 \\
\hline K-20 & 71,85 & 15,00 & 2,02 & 0,50 & 0,42 & 4,06 & 4,53 & 0,27 & 0,08 & 0,04 & 1,0 & 99,77 \\
\hline K-21 & 60,85 & 16,06 & 5,44 & 2,38 & 4,32 & 4,20 & 3,85 & 0,96 & 0,36 & 0,11 & 1,2 & 99,73 \\
\hline K-22 & 70,09 & 15,10 & 2,14 & 0,33 & 0,62 & 5,04 & 5,59 & 0,54 & 0,06 & 0,07 & 0,2 & 99,78 \\
\hline K-23 & 72,47 & 14,72 & 1,89 & 0,44 & 0,25 & 2,74 & 5,42 & 0,27 & 0,07 & 0,02 & 1,5 & 99,79 \\
\hline K-25 & 72,76 & 14,71 & 1,63 & 0,29 & 1,10 & 3,99 & 4,12 & 0,25 & 0,07 & 0,02 & 0,9 & 99,84 \\
\hline
\end{tabular}

Çizelge 2. Çalışma alanındaki volkanik birimlerin eser element jeokimyasal analiz sonuçları (eser element sonuçları ppm cinsinden verilmiştir)

\begin{tabular}{|c|c|c|c|c|c|c|c|c|c|c|c|}
\hline Örnek No & K-1 & K-2 & K-3 & K-4 & K-5 & K-6 & K-7 & K-8 & K-9 & K-10 & K-11 \\
\hline $\mathrm{Ba}$ & 903 & 730 & 671 & 1261 & 1291 & 709 & 939 & 613 & 738 & 1142 & 1008 \\
\hline $\mathrm{Co}$ & 2,5 & 10,2 & 15,6 & 0,4 & 0,8 & 2,7 & 2,1 & 11,1 & 1,3 & 1,5 & 1,3 \\
\hline $\mathrm{Cs}$ & 5,3 & 2,8 & 1,8 & 5,5 & 6,3 & 3,5 & 2 & 3,3 & 2,9 & 10,3 & 0,3 \\
\hline $\mathrm{Nb}$ & 39,1 & 24,6 & 25,1 & 30,5 & 31 & 42,1 & 25,6 & 23,6 & 42,7 & 24,6 & 24,4 \\
\hline $\mathrm{Rb}$ & 158,2 & 97,8 & 87,5 & 136,7 & 104,3 & 180,2 & 107,3 & 102 & 173,4 & 140,4 & 91,6 \\
\hline $\mathrm{Sr}$ & 189,8 & 405,9 & 443,7 & 149,3 & 130,9 & 54,9 & 184,4 & 383,7 & 52,8 & 118,3 & 258,7 \\
\hline $\mathrm{Sc}$ & 7 & 10 & 11 & 2 & 2 & 5 & 2 & 10 & 6 & 2 & 2 \\
\hline $\mathrm{Th}$ & 26,9 & 17 & 15,7 & 21 & 20,2 & 30,3 & 22,2 & 17,1 & 32,2 & 19,4 & 23 \\
\hline $\mathrm{U}$ & 8,5 & 5,2 & 4 & 4,4 & 4,2 & 8,5 & 4,4 & 4,5 & 8,6 & 4 & 5 \\
\hline $\mathrm{Zr}$ & 503,9 & 298,8 & 280,3 & 113 & 94,1 & 516,2 & 189,6 & 284,5 & 539,4 & 190,5 & 172,8 \\
\hline $\mathrm{Y}$ & 44,1 & 29,6 & 38,1 & 16,3 & 16,8 & 43,1 & 18,1 & 31,1 & 42,2 & 14,3 & 8,5 \\
\hline $\mathrm{La}$ & 78,5 & 59,9 & 81,7 & 41,4 & 40,1 & 84,5 & 63,1 & 54,9 & 79,2 & 41,5 & 34,9 \\
\hline $\mathrm{Ce}$ & 136,7 & 111 & 114,7 & 73,7 & 68,1 & 149,2 & 79,4 & 103,6 & 151,8 & 70,3 & 57,4 \\
\hline $\mathrm{Pr}$ & 15,72 & 11,69 & 15,8 & 7,31 & 6,79 & 17,13 & 10,74 & 11,16 & 16,26 & 7,17 & 6,11 \\
\hline $\mathrm{Nd}$ & 52,4 & 40,5 & 56,4 & 23,1 & 20,7 & 59 & 34,3 & 38,3 & 54,6 & 22,3 & 18,7 \\
\hline $\mathrm{Sm}$ & 9,08 & 7,57 & 9,51 & 3,54 & 3,34 & 10 & 5,11 & 6,88 & 9,89 & 3,52 & 2,89 \\
\hline $\mathrm{Eu}$ & 2,05 & 1,75 & 2,13 & 0,6 & 0,46 & 1,7 & 1,09 & 1,63 & 1,63 & 0,73 & 0,6 \\
\hline $\mathrm{Gd}$ & 8,37 & 6,56 & 8,24 & 2,82 & 2,85 & 7,88 & 3,66 & 6,42 & 8,34 & 2,68 & 1,92 \\
\hline $\mathrm{Hf}$ & 11,4 & 6,7 & 6,6 & 4,3 & 3,4 & 12,7 & 5,5 & 6,5 & 13 & 5,1 & 4,6 \\
\hline $\mathrm{Dy}$ & 7,92 & 5,55 & 7,12 & 2,6 & 2,66 & 7,68 & 3,12 & 5,5 & 7,59 & 2,74 & 1,66 \\
\hline $\mathrm{Ho}$ & 1,64 & 1,12 & 1,4 & 0,53 & 0,63 & 1,56 & 0,65 & 1,13 & 1,61 & 0,58 & 0,35 \\
\hline $\mathrm{Er}$ & 4,67 & 3,19 & 3,97 & 1,85 & 1,84 & 4,55 & 1,71 & 3,09 & 4,89 & 1,71 & 1,2 \\
\hline $\mathrm{Tm}$ & 0,71 & 0,48 & 0,6 & 0,3 & 0,29 & 0,72 & 0,29 & 0,51 & 0,73 & 0,28 & 0,19 \\
\hline $\mathrm{Yb}$ & 4,79 & 3,23 & 3,64 & 2,06 & 2,27 & 4,76 & 2,23 & 3,35 & 4,94 & 1,91 & 1,55 \\
\hline $\mathrm{Lu}$ & 0,77 & 0,5 & 0,56 & 0,34 & 0,37 & 0,75 & 0,33 & 0,5 & 0,8 & 0,31 & 0,27 \\
\hline
\end{tabular}

Volkanik birimlere ait örneklerin ana element oksitlerinin $\mathrm{SiO}_{2}$ 'ye göre ikili değişim diyagramlarında (Şekil 9) $\mathrm{Fe}_{2} \mathrm{O}_{3}, \mathrm{MgO}, \mathrm{TiO}_{2}$, $\mathrm{CaO}, \mathrm{Al}_{2} \mathrm{O}_{3}, \mathrm{P}_{2} \mathrm{O}_{5}$ değerleri $\mathrm{SiO}_{2}$ artışına bağlı olarak negatif bir trend sunmaktadırlar. $\mathrm{K}_{2} \mathrm{O}$ değerinde artış gözlenirken, $\mathrm{Na}_{2} \mathrm{O}$ değerleri dağınık bir desen sergilemektedirler. $\quad \mathrm{Al}_{2} \mathrm{O}_{3}$ içeriğinin silis miktarının artması ile plajiyoklaz kristalizasyonuna bağlı olarak düzenli bir azalma gösterdiği görülür (Şekil 9). $\mathrm{Fe}_{2} \mathrm{O}_{3}$ ve $\mathrm{MgO}$ oranlarında ise horblend ve biyotit kristalizasyonuna bağlı olarak düzenli bir azalma 
gözlenir (Şekil 9). CaO içeriğinde, kalsiyumca zengin plajiyoklazların oluşumları sonucu düzenli bir azalma gözlenmektedir (Şekil 9). $\mathrm{Na}_{2} \mathrm{O}$ içeriğine bakıldığında $\mathrm{SiO}_{2}$ artışına bağlı olarak azaldığı gözlenmektedir (Şekil 9). $\mathrm{K}_{2} \mathrm{O}$ içeriğinde K'un uyumsuz element davranışı göstermesinden dolayı $\mathrm{SiO}_{2}$ artışına paralel olarak bir artış söz konusudur (Şekil 9). $\mathrm{MnO}$ içeriği piroksen kristalizasyonuna bağlı olarak düzenli bir azalma trendi gösterir (Şekil 9). $\mathrm{TiO}_{2}$ içeriğinde piroksen (ojit) kristalizasyonuna bağlı olarak düzenli bir azalma gözlenmektedir (Şekil 9). $\mathrm{P}_{2} \mathrm{O}_{5}$ içeriği aksesuvar minerallerin fraksiyonlanması nedeniyle $\mathrm{SiO}_{2}$ artışına paralel olarak azaldığı görülür (Şekil 9).

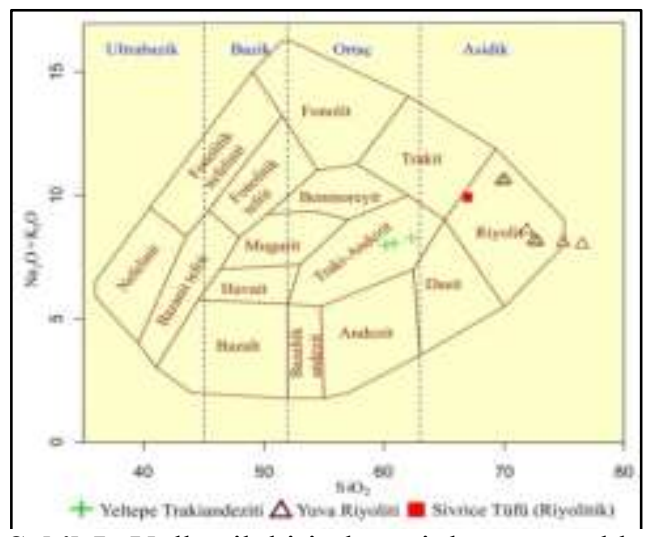

Şekil 5. Volkanik birimlere ait kayaç örneklerinin TAS adlandırma diyagramındaki konumları [15]

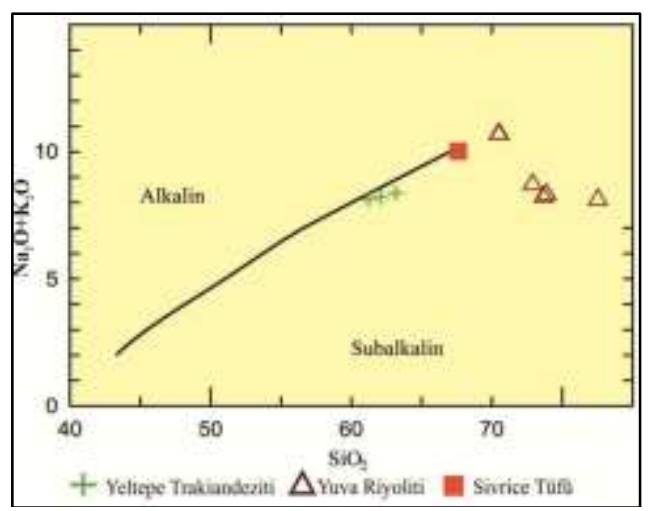

Şekil 6. Volkanik birimler için kullanılan Irvine ve Baragar [15]'in alkali-subalkali ayırtlama çizgisi

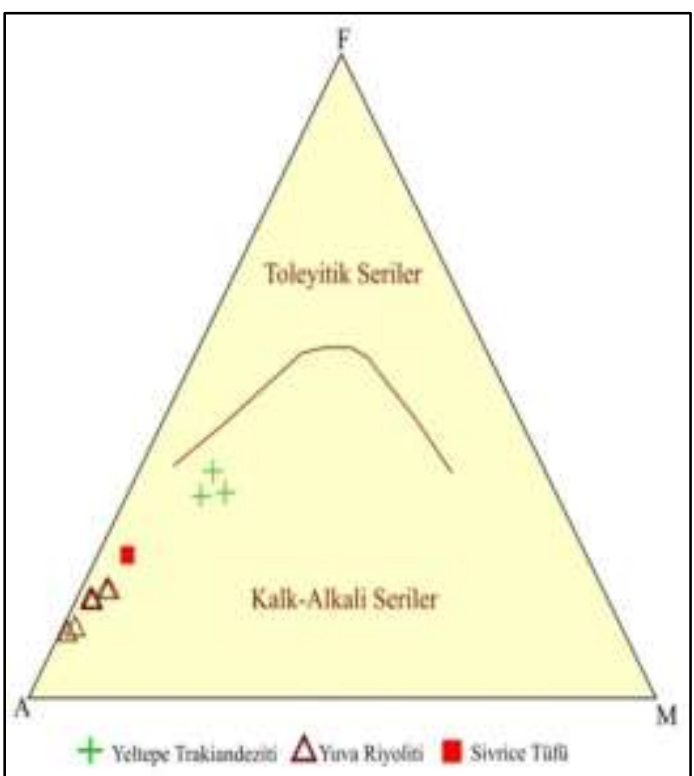

Sekil 7. Calıșma alanındaki volkaniklere ait AFM (A; $\mathrm{Na} 2 \mathrm{O}+\mathrm{K} 2 \mathrm{O}, \mathrm{F} ; \mathrm{FeO}, \mathrm{M} ; \mathrm{MgO}$ ) diyagamı [15]

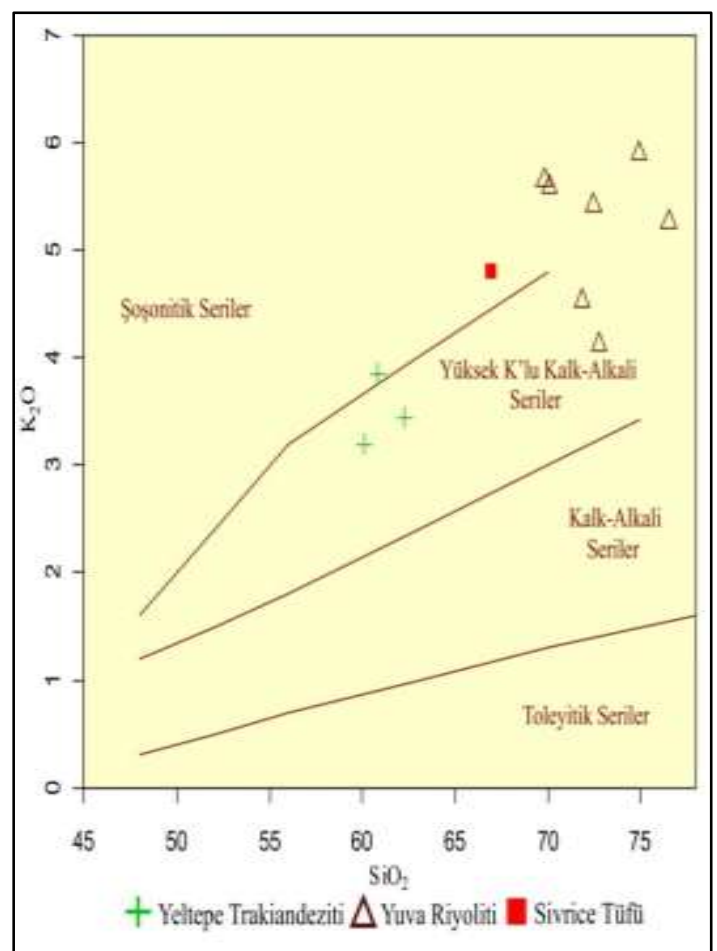

Şekil 8. Çalışma alanındaki volkaniklere ait $\mathrm{K}_{2} \mathrm{O}-\mathrm{SiO}_{2}$ diyagramı [17] 


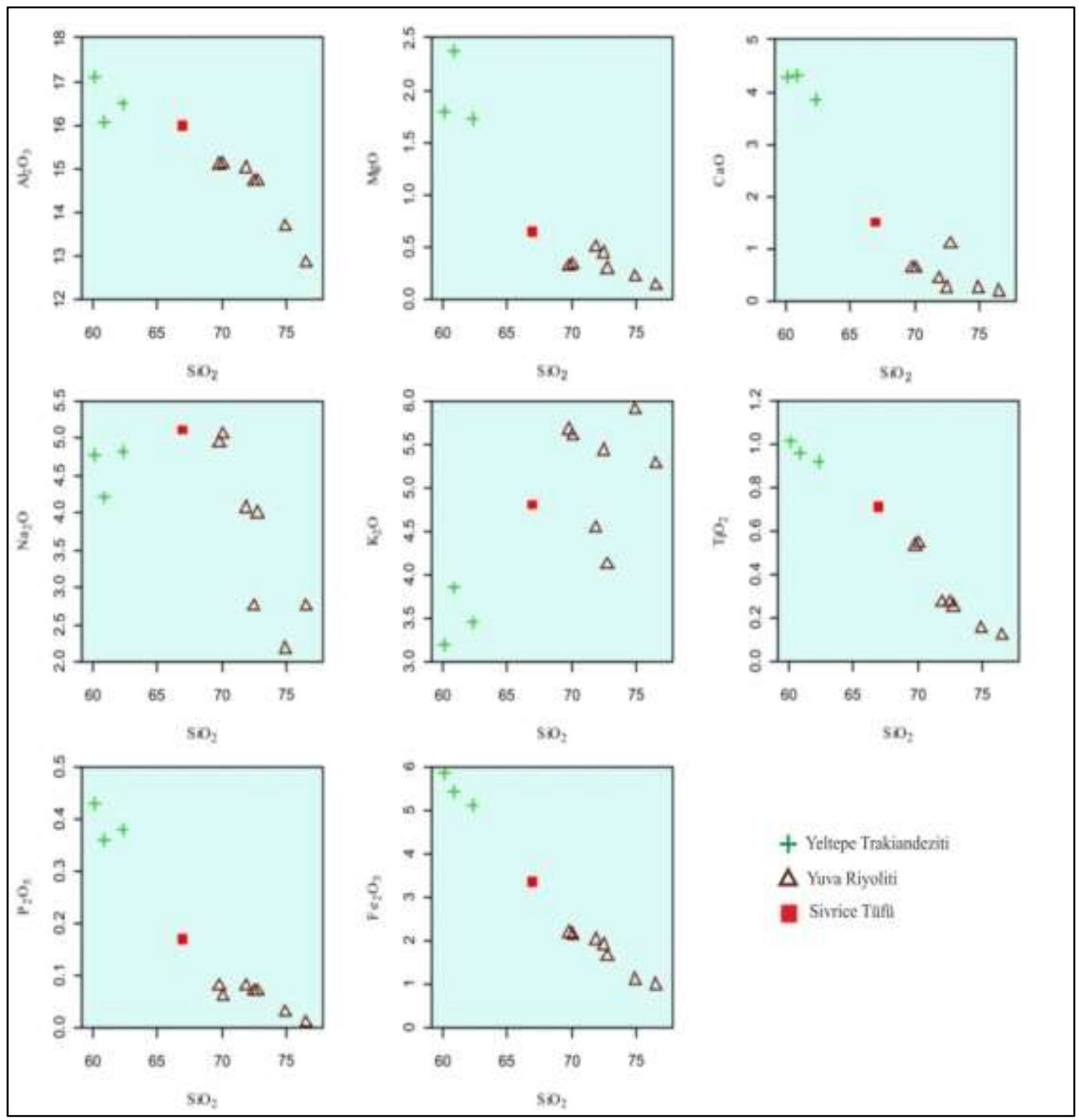

Şekil 9. Volkanik birimlere ait $\mathrm{SiO}_{2}$-ana oksit ikili değişim diyagramları

Çalışma alanındaki volkanik birimlere ait kayaç örneklerinin eser elementlerinden $\mathrm{Rb}, \mathrm{Ba}, \mathrm{Th}, \mathrm{Hf}$, $\mathrm{Sr}, \mathrm{Co}, \mathrm{Sc}$ ve Cs'un $\mathrm{SiO}_{2}$ 'ye göre değişimi diyagramlarında incelendiğinde bu elementlerden $\mathrm{SiO}_{2}$ ile uyumsuz elementlerden $\mathrm{Rb}, \mathrm{Ba}$, Th, Hf ve Cs arasinda pozitif trend gözlenirken; $\mathrm{Sr}, \mathrm{Co}$ ve $\mathrm{Sc}$ gibi uyumlu elementler arasında ise negatif bir ilişki gözlenmektedir. $\mathrm{Bu}$ durum, klasik fraksiyonel kristalleşme trendlerine işaret etmektedir. Fraksiyonel kristalleşmede, $\mathrm{Sr}^{\prime}$ un $\mathrm{SiO}_{2}$ artışına karşılık azalma göstermesi Sr'un plajiyoklazlarda $\mathrm{Ca}$ elementinin yerini alması ve Ca'ca zengin plajiyoklazların fraksiyonlanması ile ilişkilidir. Co ve Sc olivin, klinopiroksen ve mikalardaki $\mathrm{Mg}$, Fe ve Al'un yerini almasından dolayı, bu minerallerin fraksiyonlanması ile artık 
eriyiklerde, bu elementlerin miktarları gittikçe azalır. $\mathrm{Bu}$ nedenle $\mathrm{SiO}_{2}$ ile negatif korelasyon göstermektedir.

$\mathrm{Rb}$, iyonik yarıçapının K'a yakın olması nedeni ile $\mathrm{K}$ 'un yerini alır ve fraksiyonel kristalleşme sırasında K-feldispat, hornblend, biyotit gibi minerallerinin bünyesine girer. Fraksiyonel kristalleșme sırasında, bu mineraller daha geç evrelerde kristalleştiğinden, $\mathrm{SiO}_{2}$ ile pozitif bir korelasyon sunmaktadır. $\mathrm{Ba}, \mathrm{Th}, \mathrm{Cs}$ ve $\mathrm{Hf}$ elementleri de $\mathrm{Rb}$ 'a benzer davranış sergilemelerinden dolayı fraksiyonlanmanın geç evrelerinde oluşan minerallerin yapısında yer alırlar ve $\mathrm{SiO}_{2}$ ile pozitif bir korelasyon gösterirler (Şekil 10).

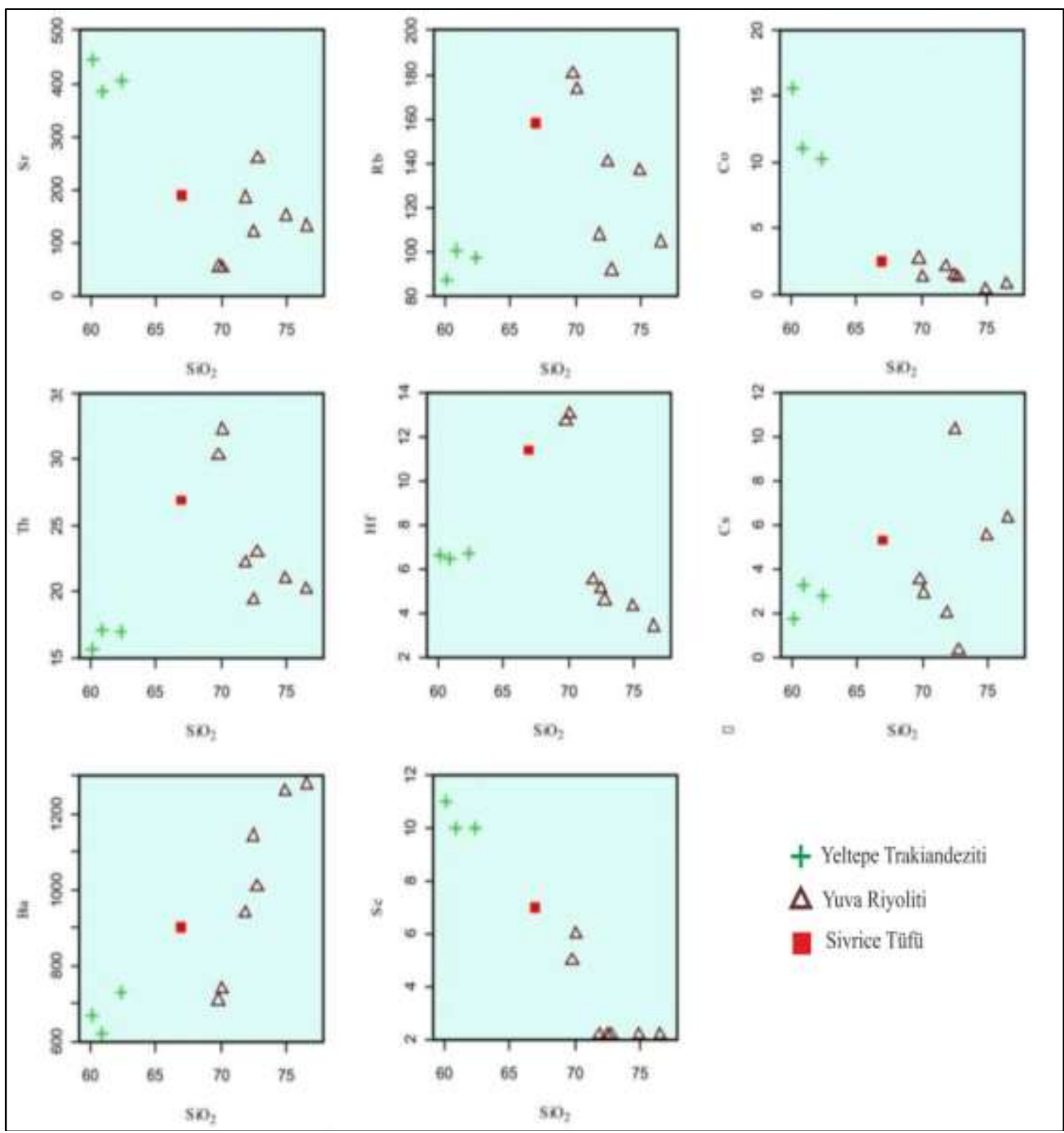

Şekil 10. Volkanik birimlere ait $\mathrm{SiO}_{2}$-eser element ikili değişim diyagramları 
Kondrit ve ilksel mantoya göre normalize edilen iz element ve nadir toprak elementleriyle ilişkili örümcek diyagramlarında (Şekil 11, Şekil 12) Cs, $\mathrm{Rb}$, Ba gibi iri katyonlu litofil elementler (LILE) ve $\mathrm{Th}, \mathrm{U}, \mathrm{Ce}$ ve $\mathrm{Nb}$ gibi yüksek değerlikli katyonlar (HFS) açısından; aynı şekilde hafif nadir toprak elementleri (LREE) açısından ağır nadir toprak elementlere (HREE) nazaran gözle görülür bir zenginleşme dikkat çekmektedir. Bu hafif nadir toprak elementlerindeki ve irikatyonlu litofil elementlerdeki zenginleşmeler kabuksal kirlenmeyi işaret etmektedir. Aynı diyagramlarda Eu'da görülen negatif anomali ise feldispat minerallerinin fraksiyonlanması sirasında adı geçen elementin bu minerallerin bünyesine girmesi nedeniyledir.

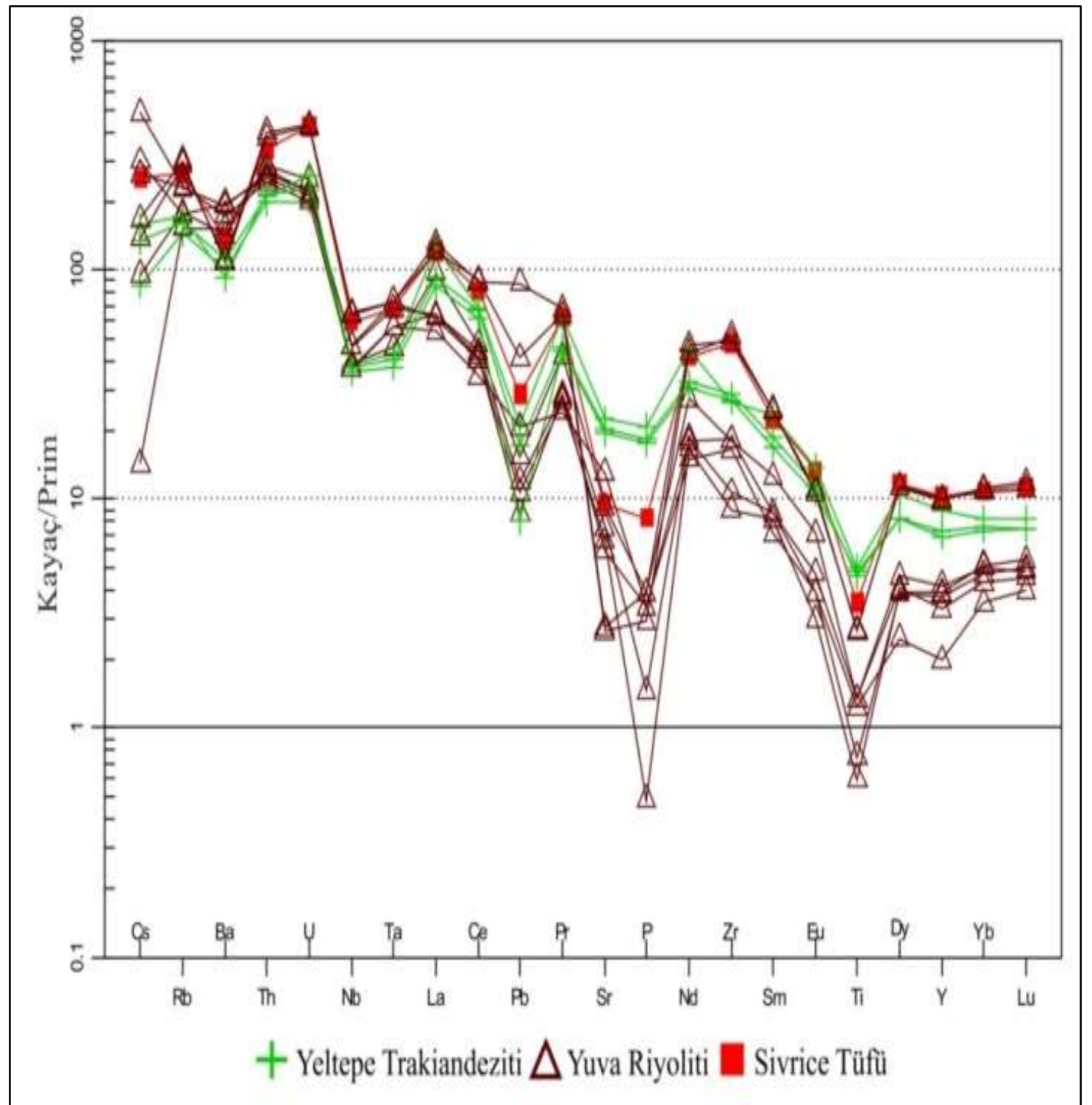

Şekil 11. Volkanik birimlerin Kayaç/İlksel manto’ya göre normalize edilmiş eser element değişim diyagramı (Normalize değerleri Sun ve Mc Donough [19]'dan alınmıştır) 


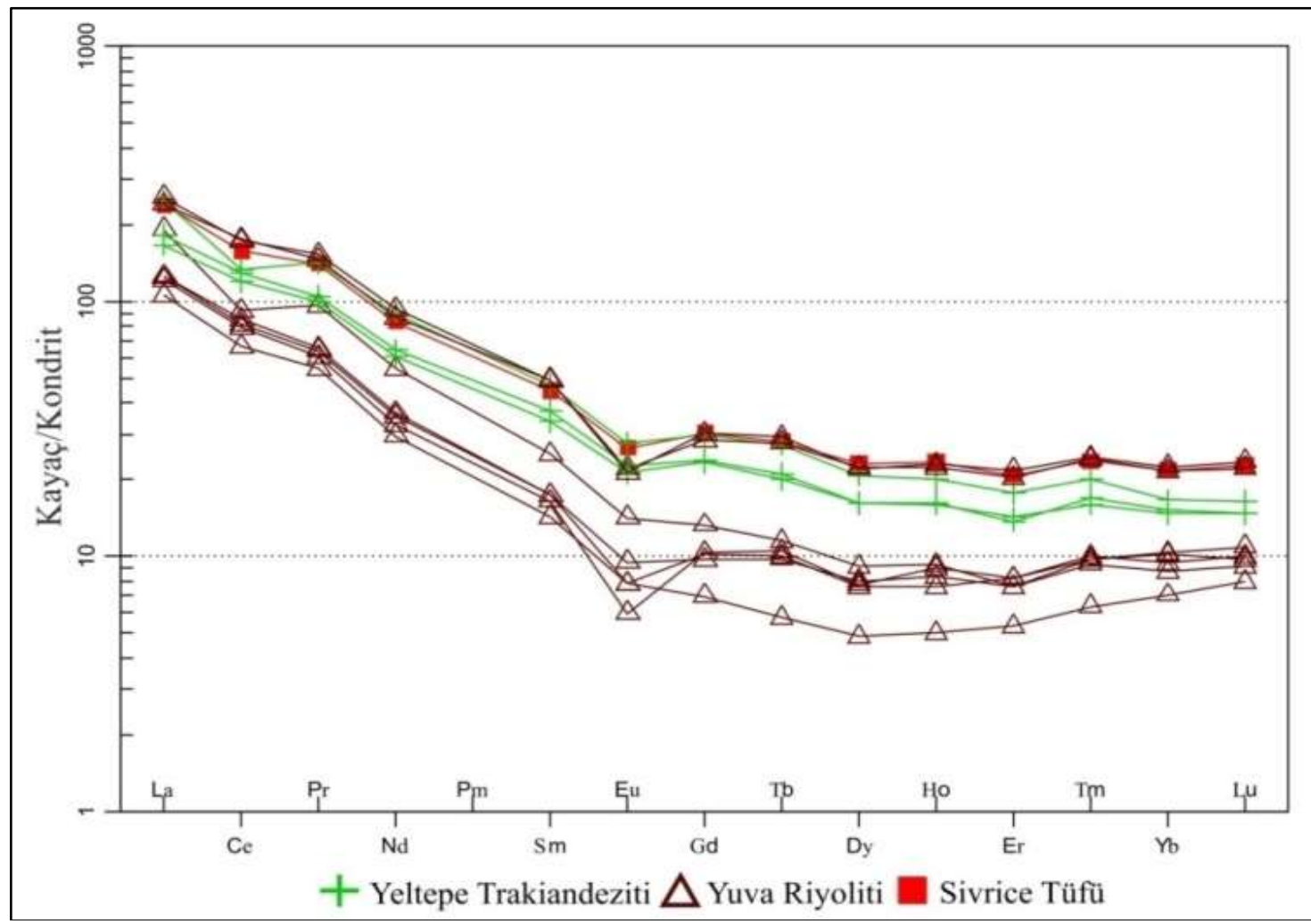

Şekil 12. Volkanik birimlerin Kayaç/Kondrit'e göre normalize edilmiş eser element değişim diyagramı. (Normalize değerleri Nakamura [20]'dan alınmıştır)

\section{SONUÇLAR}

Çalışma alanındaki plütonik kayaçlar ve volkanik kayaçlar ilk kez bu çalışmada arazi düzeyinde gösterdikleri dokusal özellik ve mineralojik bileşimlerine göre farklı birimlere ayrilarak haritalanmıştır.

Çalışma alanında bulunan plütonikler, Taşlıçay Granitoidi olarak tanımlanmış olup başlıca tonalit, granodiyorit, monzogranit ve granit bileşiminde; volkaniklerin ise riyolit ve trakiandezit bileşiminde kayaçlardan oluşmaktadırlar.

Jeokimyasal incelemeler sonucunda, bu birimlerin subalkali, kalkalkali, yüksek K'lu seri ve şoşonitik

özellik sergiledikleri ve $\mathrm{SiO}_{2}$ 'ye göre değişim diyagramlarında $\mathrm{Fe}_{2} \mathrm{O}_{3}, \mathrm{MgO}, \mathrm{TiO}_{2}, \mathrm{CaO}, \mathrm{Al}_{2} \mathrm{O}_{3}$, $\mathrm{P}_{2} \mathrm{O}_{5}$ değerleri $\mathrm{SiO}_{2}$ artışına bağlı trakiandezitlerden riyolitlere doğru bir azalma görülmektedir. Toplam alkali $\left(\mathrm{Na}_{2} \mathrm{O}+\mathrm{K}_{2} \mathrm{O}\right) ; \mathrm{Rb}$ ve $\mathrm{Ba}$ oranının trakiandezitlerden riyolitlere doğru artış göstermesi bu kayaçların oluşumuyla ilişkili olarak fraksiyonel kristallenme sürecinin etkinliğine işaret etmektedir.

KONDRİT ve PRIM'e göre normalize edilen iz element ve nadir toprak elementleriyle ilişkili örümcek diyagramlarında hafif nadir toprak elementler (LREE), iri katyonlu litofil elementler (LILE) ve yüksek değerlikli katyonlar (HFS) açısından orta (MREE) ve ağır nadir toprak elemenlerine (HREE) nazaran zenginleşmeler gözlenmiştir. $\mathrm{Bu}$ zenginleşmeler kabuksal kirlenmeyi işaret etmektedir.

\section{Katkı Belirtme}

Bu çalışma Van Yüzüncü Y1l Üniversitesi Bilimsel Araştırma Projeleri Başkanlığı tarafindan 
2014-FBE-YL187 No’lu yüksek lisans tez projesi olarak desteklenmiştir.

\section{KAYNAKLAR}

1. McKenzie, D.P., 1972. Active Tectonics of the Mediterranean. Geophysical Journal of the Astronomical Society 30, 109-185.

2. Innocenti, F., Mazzuoli, R., Pasquare, G., Radicati di Brozolo, F., Villari, L., 1976. Evolution of Volcanism in the Area of Interaction between the Arabian, Anatolian and Iranian Plates Lake Van, Eastern Turkey. Journal of Volcanology and Geothermal Research 1, 103-112.

3. Innocenti, F., Mazzuoli, R., Pasquare, G., Serri, G., Villari, L., 1980. Geology of the Volcanic Area North of Lake Van, Turkey. Geologische Rundschau 69, 292-322.

4. Innocenti, F., Manetti, P., Mazzuoli, R., Pasquare, Villari, L., 1982. Anatolia and Northwestern Iran. In: Thorpe, R.S. (Ed.), Andesites: Orogenic Andesites and Related Rocks. Wiley, 327-349, New York.

5. Yılmaz, Y., Şaroğlu, F., Güner, Y., 1987. Initiation of the Neomagmatism in East Anatolia. Tectonophysics 134, 177-199.

6. Pearce, J.A., Bender, J.F., De Long, S.E., Kidd, W.S.F., Low, P.J., Guner, Y., Şaroğlu, F., Yilmaz, Y., Moorbath, S., Mitchell, J.G., 1990. Genesis of Collision Volcanism in Eastern Anatolia, Turkey. Journal of Volcanology and Geothermal Research 44, 189-229.

7. Keskin, M., Pearce, J.A., Mitchell, J.G., 1998. Volcano-stratigraphy and Geochemistry of Collision-related Volcanism on the ErzurumKars Plateau, North Eastern Turkey. Journal of Volcanology and Geothermal Research 85, 355-404.

8. Şengör, A.M.C., Özeren, S., Genc, T., Zor, E., 2003. East Anatolian High Plateau As A Mantle-supported, North-south Shortened Domal Structure. Geophysical Research Letters 30 (24), 8045. doi:10.1029/2003GL0117858.

9. Barazangi, M., Sandvol, E., Seber, D., 2006. Structure and Tectonic Evolution of the Anatolian Plateau in Eastern Turkey. In: Dilek,
Y., Pavlides, S. (Eds.), Geological Society of America Special Paper, 409, 463-473.

10. Özdemir, Y., Karaoğlu, Ö., Tolluoğlu, A.Ü., Güleç, N., 2006. Volcano Stratigraphy and Petrogenesis of the Nemrut Stratovolcano (East Anatolian High Plateau): the Most Recent PostCollisional Volcanism in Turkey. Chem. Geol. 226 (3-4), 189-211. http://dx.doi.org/10.1016/ j.chemgeo.2005.09.0209.

11. Şengör, A.M.C., Özeren, M.S., Keskin, M., Sakınç, M., Özbakır, A.D., Kayan, I., 2008. Eastern Turkish High Plateau as a Small Turkic-type Orogen: Implications for Postcollisional Crust-forming Processes in Turkictype Orogens. Earth Science Reviews 90, 1-48.

12. Çolakoglu, A.R., Günay, K., Göoncüoglu, M.C., Oyan, V., Erdogan, K., 2014. Geochemical Evaluation of the Late Maastrichtian Subduction-related Volcanism in the Southern Neotethys in Van area, and a Correlation Across the Turkish-Iranian Border. Ofioliti 39 (2), 51e65.

13. Oyan, V., Keskin, M., Lebedev, V.A., Chugaev, A.V., Sharkov, E.V., 2016. Magmatic Evolution of the Early Pliocene Etrüsk Stratovolcano, Eastern Anatolian Collision Zone, Turkey, LITHOS, 256-257, 88-108.

14. Rolland, Y., 2017. Caucasus Collisional History: Review of data from East Anatolia to West Iran. Gondwana Research. doi: 10.1016/j.gr.2017.05.005

15. Cox, K.G., Bell, J.D., Pankhurst, R., 1979. The Interpretation of Igneous Rocks. George Allen \& Unwin.

16. Irvine, T.N., Baragar, W.R.A., 1971. A Guide to the Chemical Classification of Common Volcanic Rocks. Canadian Journal of Earth Sciences, 8, 523-548.

17. Peccerillo, A., Taylor, S.R., 1976. Geochemistry of Eocene Calc-alkaline Volcanic Rocks from the Kastamonu area, northern Turkey. Contributions to Mineralogy and Petrology, 58, 63-81.

18. Turgut, İ.K., Açlan, M., 2016. Şekerbulak (Diyadin-Ağrı) Dolaylarında Yüzeyleyen Kayaçların Mineralojik-Petrografik İncelenmesi. Van Yüzüncü Y1l Üniversitesi 
Şekerbulak (Diyadin-Ağrl) Dolaylarında Yüzeyleyen Volkanik Kayaçların Mineralojik-Petrografik ve Jeokimyasal Özellikleri

Fen Bilimleri Enstitüsü Yüksek Lisans Tezi. Aralık. s.89 (yayınlanmamış).

19. Sun, S.S., McDonough, W.F., 1995. Copmosition of the Earth. Chemical Geology 120: 223-253. Doi: 10.1016/0009. 2541(94)00140-4.

20. Nakamura, N., 1974. Determination of REE, $\mathrm{Ba}, \mathrm{Fe}, \mathrm{Mg}, \mathrm{Na}$, and $\mathrm{K}$ in Carbonaceous and Ordinary Chondrites, Geochimica et Cosmochimica Acta 38, 757-775. 